LUBLIN STUDIES IN MODERN LANGUAGES AND

LITERATURE 40(1), 2016, HTTP://WWW.LSMLL.UMCS.LUBLIN.PL, HTTP://LSMLL.JOURNALS.UMCS.PL

Jolanta Szpyra-Kozłowska

Maria Curie-Skłodowska University, Pl. M. C. Skłodowskiej 5, 20-031 Lublin, Poland

Sławomir Stasiak

Liceum Ogólnokształcące im. KEN, ul. Staszica 5, 37-450 Stalowa Wola, Poland

\title{
Verifying a holistic multimodal approach to pronunciation training of intermediate Polish learners of English
}

\begin{abstract}
The paper is an attempt to verify empirically a holistic multimodal approach to pronunciation training developed by Szpyra-Kozłowska (2015). It reports on a phonodidactic experiment carried out with two groups of Polish secondary school intermediate learners of English and demonstrates that the tested procedure is both more effective that the traditional imitation tasks and more attractive to the participants, as shown in a post-test questionnaire study.

Keywords: pronunciation teaching, phonodidactics, a holistic multimodal approach
\end{abstract}

1. Introduction

Contemporary studies on teaching English pronunciation to second language learners (e.g. Kenworthy 1987, Pennington 1987, Morley 1991, Brown 1992, Dalton and Seidlhofer 1994, Celce-Murcia et al. 
1996, Kelly 2000, Hewings 2004, Fraser 2006, Gilbert 2008, Rogerson-Revell 2011 - to mention only several well-known booklength publications) abound in numerous interesting ideas, meant to improve the quality of phonodidactic instruction. The authors of these and many other works introduce and discuss various both traditional as well as innovative pronunciation teaching and learning techniques. The former include, for instance, phonetic drills of many kinds, imitation activities which make use of tongue twisters, poems, songs and minimal pairs, employing phonemic transcription, sound charts, articulatory descriptions and elements of contrastive phonetics etc. The latter involve, for example, developing in learners native-like articulatory setting (Jenner 1997, Mompean-Gonzales 2003), appealing to different channels of perception and processing of information, employing relaxation and drama voice techniques, pronunciation games, computer-assisted pronunciation training and many others.

While numerous phonodidactic proposals have been put forward in the recent years, their effectiveness in the pronunciation teaching and learning process, however, has rarely been subject to empirical verification. In other words, it is not always clear whether some new and interesting ideas are indeed pedagogically justified and bring the desired improvement in learners' pronunciation. This issue is particularly important in a typical school context in countries such as Poland in which only a limited amount of time is devoted to pronunciation instruction (Wrembel 2002, Szpyra-Kozłowska 2008). In this situation it is of primary importance for teachers to focus on the use of those techniques which yield the best results rather than waste precious classroom time on attractive, but ineffective tasks. Before, however, informed decisions can be made in this respect, the effectiveness of various instructional procedures should be tested in specific educational settings and with different kinds of learners.

Szpyra-Kozłowska (2015), in an attempt to answer the question how to teach English pronunciation in a way that is both effective and at the same time attractive, which is both learner-friendly and teacherfriendly, develops a holistic multimodal approach to EFL 
phonodidactics arguing that it should cater for students' different learning styles by combining elements of auditory, articulatory, cognitive and multisensory training. She provides no empirical evidence, however, to show that this proposal is indeed superior to other approaches, in particular to the traditional and commonly used type of instruction (see below) which relies heavily on aural and oral training, with little or no use of other learning modalities.

The present study attempts to verify the effectiveness of the approach under discussion. It is a report on an experiment, carried out with 28 Polish teenage intermediate learners of English, who, for the period of three months, were taught selected aspects of English pronunciation in two ways: in Group A mainly the traditional 'intuitive-imitative' activities (Celce-Murcia et al. 1996) were employed while in Group B the holistic multimodal approach was adopted. The experiment aimed at answering the following research questions:

- Which procedure, i.e. an 'intuitive-imitative' approach or a holistic multimodal training brings better improvement in Polish learners' English pronunciation?

- How do students with different learning styles evaluate the holistic multimodal training?

A comment on the choice of the 'intuitive-imitative' activities, juxtaposed with a multimodal approach in this study is in order. Although, as mentioned earlier, a variety of pronunciation teaching techniques have been suggested in the literature, in the Polish educational context the traditional imitation tasks constitute the basis of phonetic training and are the most frequently (and often the only) employed types of pronunciation activities (see, e.g. Wrembel 2002, Szpyra-Kozłowska 2008). According to Celce-Murcia et al. (1996: 2), "an Intuitive-Imitative Approach depends on the learner's ability to listen to and imitate the rhythms and sounds of the target language without the intervention of any explicit information."

${ }^{1}$ Celce-Murcia et al. (1996: 2) contrast it with an analytic-linguistic approach which "utilizes information and tools such as a phonetic alphabet, articulatory descriptions, 
2. A holistic multimodal pronunciation teaching

Szpyra-Kozłowska (2015) argues that effective pronunciation instruction should be holistic and should develop in learners, to use Dalton and Seidlhofer's (1994) terms, 'sounds in the body' and 'sounds in the mind.' Toward this purpose, she proposes a holistic multimodal approach to phonetic training which combines elements of auditory, articulatory, cognitive and multisensory training. The four components of this approach can be briefly characterized as follows:

Articulatory training, traditionally employed in phonetic instruction, is aimed at the formation of new motor habits needed to pronounce new sounds and sound sequences. Different types of drills should be employed e.g. using minimal-pairs (word-level and sentence-level drills), contextualized minimal pairs, tongue twisters and developmental approximation drills (Celce-Murcia et al. 1996) in order to achieve automaticity in the production of foreign sounds. Drills must be followed, however, by communicatively-oriented activities in which the drilled items appear in a variety of meaningful contexts. Communicative pronunciation activities, which focus on meaningful practice are necessary to foster phonetic 'carry over' from the classroom to real-life situations (Morley 1991). An important part of articulatory training consists in developing in learners native-like articulatory setting, which helps them to improve the quality of their English pronunciation (Jenner 1997, Święciński 2006).

Auditory training, also found in traditional instruction, is needed to foster learners' comprehension of spoken English as well their phonetic progress. It should initially involve basic tasks such as, for instance, sound discrimination, noticing various phonetic features of L2 and differences between sounds and prosodic patterns of L1 and L2. At more advanced levels students' receptive skills ought to be

charts of the vocal apparatus, contrastive information, and other aids to supplement listening, imitation, and production. It explicitly informs the learner of and focuses attention on the sounds and rhythms of the target language." In the holistic multimodal approach, intuitive-imitative techniques are part of articulatory and auditory training, and analytic-linguistic activities belong to cognitive training. 
developed in order to improve their comprehension of different accents of English. An important principle of EFL students' pronunciation training should be the maximization of phonetic input, i.e. surrounding them with sounds of English both in the classroom and outside it in an attempt to imitate at least partially natural conditions of learning.

Articulatory and auditory training belongs not only to the traditional pronunciation teaching, but also constitutes an indispensable component of the multimodal approach advocated by Szpyra-Kozłowska (2015). Nevertheless, in her proposal two other types of training occupy a prominent position.

Cognitive phonetic and phonological training should complement articulatory and auditory instruction in order to enhance learners' understanding of the basics of L1 and L2 phonetics and phonology through developing their phonetic metacompetence and raising their phonological awareness (Celce-Murcia et al. 1996, Wrembel 2005). It involves providing students with explicit information on selected aspects of L1 and L2 sound articulation and prosodic properties, comparing L1 and L2 sound systems (contrastive analysis), discussing particularly important aspects of phonetic and phonological interference from L1 on L2. Learners can also get acquainted with various elements of the phonological system of L2, such as selected phonotactic constraints and phonological processes, and compare them with those of L1 (Szpyra-Kozłowska 2002). A problem-solving approach to these issues is advocated as beneficial for internalizing theoretical knowledge. This type of training is particularly important in the case of adult learners who need to understand what they are required to do. Thus, we promote conscious pronunciation learning and agree with Fraser (2006: 4), who argues that "pronunciation is a cognitive skill...[which] involves both 'knowing' things about language and being able to do things physically with the body." Also Moyer (2013: 3) maintains that "phonology is unique compared to other language realms because it relies on both motor-based and cognitive skills for perception and production." 
Multisensory training (e.g. Celce-Murcia et al. 1996, Wrembel 2010) caters for the needs of students with different learning modalities (auditory, visual, tactile and kinesthetic) and complements other types of instruction. It activates various channels of perception in the course of holistic phonetic training and integrates auditory, visual, tactile and kinesthetic learning by employing different kinds of multisensory reinforcement. Due to it multimodal learners acquire L2 pronunciation easier and faster as it allows for better comprehension and deeper processing of information. Moreover, it makes phonetic training more attractive and motivating to students. As observed by Sankey, Birch and Gardiner (2010: 854), "students engaged in learning that incorporates multimodal designs, on average, outperform students who learn using traditional approaches with single modes."

Szpyra-Kozłowska (2015) argues that the most effective phonetic activities are those which incorporate several kinds of multimodal reinforcement, meant to benefit different types of learners. Ear training is particularly beneficial to auditory learners, phonemic transcription and other visual aids (sound charts, diagrams, head cross-sections etc) appeal primarily to visual students while various games involving movement and the use of props as well as dramarelated activities are ideally suited to the kinesthetic learning style. Since in all instances the formation of the English sound system in the learners' minds should be aimed at, cognitively-based activities like introducing elements of phonology or games which raise language awareness are also advocated. Thus, ideally, various techniques should be employed in the course of holistic phonetic training and applied to each phonetic issue which is being learnt. While individual elements present in this approach are well-known and have been postulated separately in various publications on English phonodidactics, it is an attempt to develop and integrate them into a coherent method to be applied in EFL phonetic training that makes it novel. 


\section{Study}

Below we present some relevant details regarding the experiment: its participants and their learning styles, the diagnostic passage, the preexperimental recordings and their results, and the experimental training.

\subsection{Participants}

The participants were two classes of 16 year-old students of both sexes (28 altogether) attending a senior secondary school in Stalowa Wola and taught English by one of the authors (S. Stasiak). The students represented the pre-intermediate to intermediate level of general English proficiency, as shown by regular evaluation tests carried out by their teacher. The same cannot be said about their English pronunciation, assessed by the experimenters as very poor, due to the almost total neglect of phonetic training at the earlier stages of their education.

Prior to the experiment, they were asked to complete Learning Styles Modality Preference Inventory ${ }^{2}$ in order to determine their strength in the visual, auditory, kinesthetic/tactile modalities.

Let us characterize different kinds of learners briefly.

Visual learners need to see something in order to understand and remember it. Typically they have to take notes and write everything down.

Auditory learners activate mainly their aural channel so they have to hear what they are to learn. Oral lectures and recordings appeal to them far more than written materials.

Kinesthetic / tactile students' learning is largely enhanced through body movement and a sense of touch.

The following modalities were identified among the students.

\footnotetext{
${ }^{2}$ It is available at https://api.ed2go.com/CourseBuilder/2.0/images/resources/prod/hss-

0/LearningStyles.pdf. This test has been selected for our study out of many available options mainly because of its fairly simple formulation of questions to be responded to, suitable for intermediate learners.
} 
Table 1. Strongest modalities of 28 participants

\begin{tabular}{|cc|}
\hline Strongest modalities & Number of participants \\
\hline visual & $\mathbf{5}$ \\
\hline auditory & 1 \\
\hline kinesthetic & $\mathbf{7}$ \\
\hline visual-kinesthetic & $\mathbf{1 3}$ \\
\hline visual-auditory & 1 \\
\hline auditory-kinesthetic & 1 \\
\hline
\end{tabular}

Table 1 shows that among 28 students the largest group are visualkinesthetic (13), kinesthetic (7) and visual (5) learners, while those with the strongest auditory modality constitute a minority ( 3 pupils). These results coincide with those found in other studies (e.g. Bukowski 2003) and suggest that basing pronunciation training on aural input only is of a limited appeal to learners with a weak auditory modality.

\subsection{The diagnostic passage}

For the purposes of the experiment a diagnostic passage (see Appendix 1), suitable for intermediate learners in terms of vocabulary and grammar, was written by the experimenters. It contained several words and phrases (see Appendix 2) with many occurrences of each of the tested phonetic features (specified below). Any words judged by the teacher to be unknown to the students were pre-taught to them before the recording was made.

\subsection{The pre-experimental recording}

In each class 5 pupils were randomly selected for the subsequent recordings (both pre-experimental and post-experimental). They were given the diagnostic passage to read silently. Next they were individually recorded in a secluded room, in stress free atmosphere. It was explained that the recordings were needed for research concerning difficulties of Polish students with English pronunciation.

The following aspects of English pronunciation, known to be problematic for Polish learners, were selected for the purposes of the experiment: the interdental fricatives, the palatoalveolars, the regular 
forms with the inflectional -(e)d endings, strong and weak forms of modal verbs (can, could, must, should) and word stress in items with stress-neutral suffixes (e.g. -ing,-ed, -ness, -ment, -er, -ly).

The interdentals, absent in Polish, are commonly replaced by Polish learners with either the dental plosives $/ \mathrm{t}, \mathrm{d} / \mathrm{or}$ the labio-dental fricatives /f, v/ (less frequently with dental /s, z/) (e.g. mother [maver] / [mader]). English palatoalveolars i.e. $/ \int, 3, t 5, d_{3} /$ are usually substituted by Poles with their Polish postalveolar equivalents. The final consonant in the regular past tense suffix is typically devoiced (e.g. moved is usually pronounced as [muft] and sorted pronounced as [sortit]), in agreement with the Polish rule of Final Obstruent Devoicing. Additionally, the selection of the syllabic and nonsyllabic allomorphs is also problematic to many learners (e.g. judged frequently mispronounced as [dzadzit]). As Polish has no weak forms, and no stress-neutral affixes, these phenomena are also a source of pronunciation difficulties. Typically Poles employ strong forms only (e.g. I can go ['aj 'ken 'gow]) and tend to stress penultimate syllables, e.g. fasci'nating, tole'rated (Sobkowiak 1996).

The analysis of the pre-test recordings has shown that none of the five aspects of English pronunciation tested in this study has been acquired properly by the 10 recorded participants. This means that the selected features found in the diagnostic items (see Appendix 2) were not pronounced correctly by them and were rendered in typically Polish ways specified above. ${ }^{3}$ The same observation holds true of the participants from Group A and Group B.

\subsection{Experimental phonetic training}

Within the three-month experimental period Group A and Group B were taught five phonetic issues, specified in section 3.3.

- Group A - was taught pronunciation by means of imitation activities only

\footnotetext{
${ }^{3}$ The recordings were assessed by the experimenters auditorily. In cases of doubt spectrographic analysis was employed.
} 
- Group B - was taught pronunciation holistically, in a manner described below

In both groups the same amount of time was devoted to pronunciation training, i.e. about 10 minutes per lesson (3 times a week). For reasons of space limitations all the activities employed in the course of phonetic training cannot be described here in detail. Below we present the employed approach only to two selected issues: the interdental fricatives and inflectional endings.

\subsubsection{The interdental fricatives}

A problem notoriously difficult for many foreign learners of English is the pronunciation of the interdental fricatives, absent in the majority of languages. We adopted the following procedure to teach these sounds in the experimental group.

First, some sound discrimination tasks were employed. In one of them learners placed the following phonetic symbols on separate cards, with the interdentals marked with a different colour: /t, $\mathrm{d}, \mathrm{f}, \mathrm{v}, \mathrm{s}$, $\mathrm{z}, \Theta, \partial /$. Then the teacher read a list of minimal pairs which begin with these consonants, e.g. fin - thin, sink - think, ten - then, tank - thank, day - they, tree - three. After listening to each pair the students raised the appropriate two symbols representing the sounds they heard. If the answers were incorrect, the teacher repeated a given word pair.

Next the teacher read a variety of words with different consonants and the pupils' task was to raise a card with the transcription symbols representing the interdentals if such a sound was found in a given item, e.g. bass, bathe, Beth, mother, mutter, frill, thrill, father, fuss, butter, bother, brother. The words with the 'th' consonants were then repeated (chorally and individually).

A game-like multimodal activity followed. The teacher prepared several cards with nouns containing interdentals which were familiar to the learners, e.g. earth, thief, birthday, father, weather, clothes. A selected student presented the content of a given item by means of gestures or drawings. The remaining learners tried to guess which word it was with a prompt that it comprised a 'th' consonant, and repeated the item after the teacher. Body movements and gestures 
were also employed to express the meaning of such verbs as thank, think, throw, thread, bathe, breathe or more difficult nouns like depth, length, width, strength.

The next task required students to write sentences which contained as many words with the interdentals as possible, e.g.

His mother, father and brother gave him three things for his thirtieth birthday.

I think this thin thief with bad teeth was not as healthy as he thought.

The most interesting sentences were then selected by pupils for oral practice.

Then a simplified articulatory description followed. The teacher explained in Polish the difference in the articulation of the relevant fricative pairs: /f, v/, /s, z/ and / $\Theta, \partial /$ by showing that in the first case a gap occurred between the lower lip and the upper teeth, in the second between the tip of the tongue and the back of the upper teeth (in Polish) and the alveolar ridge (in English) and for the English interdentals the tip of the tongue is usually placed between the upper and the lower teeth ${ }^{4}$. The students were encouraged to use mirrors to observe the action of visible articulators.

Next, the relevant sequences of fricatives, i.e. /f/, /s/, / $/ \Theta$ and $/ \mathrm{v} /$, $\mathrm{z} /, / ð /$, were practiced in minimal pairs, e.g. fin - sin - thin, sing thing, fought - thought, sink - think, mouse - mouth.

Subsequently, the instruction focused on the differences between the interdentals and the corresponding Polish plosives, i.e. E/ $/ \mathrm{O} /$ and $\mathrm{P} / \mathrm{t} /, \mathrm{E} / \delta /$ and $\mathrm{P} / \mathrm{d} /$, with an explanation that to pronounce $\mathrm{E} / \Theta /$, the learners can first produce Polish / $t /$ and then remove the tip of the tongue from the upper teeth slightly to form a small narrowing through which the air should be pushed out. The same was done with regard to $\mathrm{E} / \mathrm{\delta} /$ and $\mathrm{P} / \mathrm{d} /$. Bilingual near minimal pairs were then employed for practice, e.g. P tynk 'plaster' - E think, $\mathrm{P}$ tam 'there'- E thumb, $\mathrm{P}$ tyk 'tick' - E thick, $\mathrm{P}$ tryl 'trill' - E thrill, $\mathrm{P}$ pat 'stalemate'E path.

\footnotetext{
${ }^{4}$ It is possible to pronounce the consonants in question also in some other ways (see Cruttenden 2008), but the interdental articulation is the easiest to show and practice.
} 


\subsubsection{Inflectional endings}

The students first listened to pairs of present tense and regular past tense verb forms, such as want - wanted, work - worked, clean cleaned and repeated them first chorally, then individually.

Also, the participants were asked to prepare several sets of cards of three different colours with /t/, /d/ and /Id/ written on them.
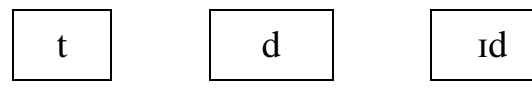

Other cards contained different regular verbs ending in a variety of consonants and vowels, e.g. want, work, mend, pick, die, love, join, wash, watch, judge, paint, rob, sail, enjoy, decide. The students' task was to match the verbs with the appropriate endings by putting paper cards from the two sets together. Then the pronunciation of regular past tense forms was practiced.

The next step involved problem solving. The participants were asked to formulate the rule responsible for the distribution of the three inflectional suffixes. The first issue to determine was the occurrence of the syllabic (/Id/) versus nonsyllabic endings (/t/ and /d/). Further, the conditions on the attachment of the voiced and voiceless suffixes were specified. This was combined with an explanation concerning word final obstruent devoicing in Polish and lack of such process in English.

Finally, the teacher produced a sentence in the present tense with some verbs from the pool and indicated a student who was to change it into the past tense at the same time showing the card with the appropriate ending to the rest of the class, e.g.

Teacher: I pull and push very hard. - Student: He pulled and pushed very hard.

Teacher: I mend and paint it all day. - Student: He mended and painted it all day.

The teacher also asked a series of questions the answers to which required the use of past tense forms, e.g.

What did he cook? Why did they move here? What did you paint? 
3.5. The post-experimental recording

After three months ten students from Group A and Group B recorded earlier were re-recorded while reading the same diagnostic passage to which they had no access during the experimental period.

\subsection{The questionnaire}

After the experiment the pupils in both groups were asked to complete a questionnaire meant to examine their assessment of the experimental phonetic training, its attractiveness and effectiveness.

4. Results

Below we present the results of 10 participants (5 from the experimental Group B, 5 from the control Group A) who were recorded prior to the experiment. As mentioned in section 3.3., in all cases the pre-experimental recordings showed $0 \%$ of the correct rendition of the tested features in the diagnostic items. The percentages in the tables below indicate the correct pronunciation of a given feature after the experiment.

Table 2. Results of the experimental group.

\begin{tabular}{|c|c|c|c|c|c|c|}
\hline & th & $\begin{array}{c}\text { Infl. } \\
\text { end. }\end{array}$ & Pal.alv & S/WF & $\begin{array}{c}\text { Word } \\
\text { stress }\end{array}$ & $\begin{array}{c}\text { Overall } \\
\text { progress }\end{array}$ \\
\hline P1 & $80 \%$ & $80 \%$ & $100 \%$ & $100 \%$ & $40 \%$ & $80 \%$ \\
\hline P2 & $100 \%$ & $40 \%$ & $100 \%$ & $80 \%$ & $80 \%$ & $76 \%$ \\
\hline P3 & $100 \%$ & $100 \%$ & $100 \%$ & $100 \%$ & $100 \%$ & $100 \%$ \\
\hline P4 & $40 \%$ & $60 \%$ & $60 \%$ & $60 \%$ & $60 \%$ & $56 \%$ \\
\hline P5 & $80 \%$ & $100 \%$ & $100 \%$ & $80 \%$ & $80 \%$ & $88 \%$ \\
\hline mean & $80 \%$ & $76 \%$ & $92 \%$ & $84 \%$ & $72 \%$ & $\mathbf{8 0 \%}$ \\
\hline
\end{tabular}

The mean progress made by the experimental group amounts to a very high figure of $80 \%$. The biggest improvement concerns the pronunciation of palatoalveolars $(92 \%)$, the smallest word stress $(72 \%)$.

Table 3 shows the results of the control group. 
Table 3. Results of the control group.

\begin{tabular}{|c|c|c|c|c|c|c|}
\hline & th & $\begin{array}{c}\text { Infl. } \\
\text { end. }\end{array}$ & Pal.alv & S/WF & $\begin{array}{c}\text { Word } \\
\text { stress }\end{array}$ & $\begin{array}{c}\text { Overall } \\
\text { progress }\end{array}$ \\
\hline P1 & $40 \%$ & $60 \%$ & $0 \%$ & $40 \%$ & $80 \%$ & $44 \%$ \\
\hline P2 & $40 \%$ & $20 \%$ & $0 \%$ & $20 \%$ & $40 \%$ & $24 \%$ \\
\hline P3 & $60 \%$ & $80 \%$ & $60 \%$ & $60 \%$ & $60 \%$ & $64 \%$ \\
\hline P4 & $80 \%$ & $20 \%$ & $40 \%$ & $20 \%$ & $80 \%$ & $48 \%$ \\
\hline P5 & $40 \%$ & $60 \%$ & $0 \%$ & $40 \%$ & $60 \%$ & $40 \%$ \\
\hline mean & $52 \%$ & $48 \%$ & $20 \%$ & $36 \%$ & $68 \%$ & $\mathbf{4 4 \%}$ \\
\hline
\end{tabular}

In this case the mean progress was $44 \%$, which is an impressive achievement, but not when compared with the twice as high result of the experimental group. The greatest improvement occurred in the case of word stress $(68 \%)$, the smallest $(20 \%)$ with regard to the palatoalveolars.

These results clearly indicate that the holistic multimodal approach to phonetic training is more effective than the traditional 'intuitiveimitative' procedure, particularly in the case of students with the dominant visual and kinesthetic/tactile learning styles, who constitute the majority of learners. ${ }^{5}$ Thus, what matters is not only the amount of time devoted to pronunciation practice, but the choice of proper instructional procedures.

Interestingly, the best and the worst mean results are exactly the opposite; in the control group the biggest progress was made with regard to the proper placement of word stress - 68\% (72\% in the experimental group), while the pronunciation of palatoalveolars improved only by $20 \%$ ( $92 \%$ in the experimental group). This suggests that the effectiveness of different teaching techniques largely depends on specific aspects of pronunciation.

5. The questionnaire

After the experiment Group B was asked to complete a short questionnaire in which the pupils evaluated the multimodal phonetic

\footnotetext{
${ }^{5}$ It should be added that the high results obtained in both groups can also be attributed to the fact that the recordings were made directly after the end of the experiment. A delayed post-test would be needed to see how durable the results of the training are.
} 
training they had received. Below we include a selection of representative opinions.

The first question was as follows: "Do you think your English pronunciation has improved in the course of the training?" Almost all the participants (12 out of 13) were of the opinion that due to the multimodal training their English pronunciation improved and only one learner chose the "I don't know" option.

The second question, i.e. "Which activities have you found particularly useful?" was meant to elicit the participants' opinions on specific activities employed in the course of phonetic training. Interestingly, cognitive and multimodal activities, but not the traditional articulatory and auditory tasks were often mentioned as particularly effective. The pupils regarded phonetic transcription as the most useful technique by commenting on it in the following way: "Due to learning phonetic symbols I can find in a dictionary how a word is pronounced." "I liked writing words in transcription and then pronouncing them aloud. I can remember them better that way."

Other cognitive activities were also positively evaluated, e.g. "I liked all tasks in which we compared the pronunciation of similar English and Polish words and explained the differences." "I had no idea there are simple and useful rules how to pronounce "edwards' (words with the -ed ending)."

These were multisensory activities, however, which received the most enthusiastic comments, e.g. "It was fun to sit in front of the mirror and watch my tongue while pronouncing 'th'." "I enjoyed raising cards with $/ \mathrm{t} /, / \mathrm{d} /$ and $/ \mathrm{Id} /$ when different verbs were pronounced by the teacher."

Finally, many pupils expressed their general views on the multimodal training, e.g. "I really needed all those activities. Now I feel more confident when I speak English." "I had no idea that learning English pronunciation could be so cool."

Negative comments were infrequent and concerned individual learner's dislike of specific activities (e.g. "I think there were too many activities with the -ed ending"), which, in view of their different learning styles, was to be expected. 


\section{Conclusion}

The results of the experiment reported in this paper demonstrate that the holistic multimodal approach to phonetic training which involves articulatory, auditory, cognitive and multisensory activities is more effective than the traditional 'intuitive-imitative' tasks since the former caters for the needs of students with different learning styles while the latter is suitable mainly for auditory learners. As kinesthetic/tactile and visual learners outnumber auditory ones, and all students employ more than one modality in the learning process, a holistic multimodal training is superior to instruction which focuses on one channel of perception and processing of information only. This means that the choice of proper instructional procedures is of primary relevance to the effectiveness of pronunciation practice.

The post-experimental questionnaire carried out among the participants revealed their very positive reactions to the multimodal training they had received. It was evaluated as not only effective, but also attractive and stimulating interest in acquiring proper English pronunciation.

\section{References}

Brown, A. (ed.). (1992). Approaches to Pronunciation Teaching. London and Basingstoke: Macmillan Publishers.

Bukowski, D. (2003). Multisensory modes in teaching and learning phonetics - a few practical suggestions. In W. Sobkowiak, E. Waniek-Klimczak (eds.), Dydaktyka fonetyki języka obcego 5. Płock: Wydawnictwo PWSZ, 11-29.

Celce-Murcia, M., Brinton, D.M., \& Goodwin, J. (1996). Teaching Pronunciation: A Reference for Teachers of English to Speakers of Other Languages. Cambridge: Cambridge University Press.

Cruttenden, A. (2008). Gimson's pronunciation of English. London \& New York: Arnold.

Dalton, Ch., \& Seidlhofer, B. (1994). Pronunciation. Oxford: Oxford University Press.

Fraser, H. (2006). Teaching Pronunciation: A Handbook for Teachers and Trainers. Sydney: TAFE NSW Access Division. Retrieved from http://helenfraser.com.au/wp-content/uploads/HF-Handbook.pdf, 
Gilbert, J. B. (2008). Teaching Pronunciation. Using the Prosody Pyramid. Cambridge: Cambridge University Press.

Hewings, M. (2004). Pronunciation Practice Activities. Cambridge: Cambridge University Press.

Jenner, B. (1997). The English voice. In A. Brown (ed.), Approaches to Pronunciation Teaching. London and Basingstoke: Macmillan Publishers, 34-46.

Kelly, G. (2000). How to Teach Pronunciation. Harlow: Longman.

Kenworthy, J. (1987). Teaching English Pronunciation. London: Longman.

Mompean-Gonzales, J. A. (2003). Pedagogical tools for teaching articulatory setting. In M. Sole, D. Recasens and J. Romero (eds.), Proceedings of the $15^{\text {th }}$ International Congress of Phonetic Sciences: Barcelona 2003. Adelaide: Casual Productions, 1603-1606.

Morley, J. (1991). The pronunciation component in teaching English to speakers of other languages. TESOL Quarterly 25(3). 481-519.

Moyer, A. (2013). The Phenomenon of Non-native Speech. Cambridge: Cambridge University Press.

Pennington, M. (1987). Phonology in English Language Teaching. An International Approach. London: Longman.

Rogerson-Revell, P. (2011). English Phonology and Pronunciation Teaching. London \& New York: Continuum.

Sankey, M., Birch, D., \& Gardiner, M. (2010). Engaging students through multimodal learning environments: The journey continues. Retrieved from www.ascilite.org.au/conferences/sydney10/procs/sankey-full.pdf.

Sobkowiak, W. (1996). English Phonetics for Poles. Poznań: Bene Nati.

Szpyra-Kozłowska, J. (2002). In defence of 'practical' phonology. In E. WaniekKlimczak and J. Melia (eds.), Accents and Speech in Teaching English Phonetics and Phonology. Frankfurt: Peter Lang, 125-137.

Szpyra-Kozłowska, J. (2008). English pronunciation pedagogy in Poland achievements, failures and future perspectives. In E. Waniek-Klimczak (ed.), Issues in Accents of English. Newcastle: Cambridge Scholars Publishing, 212234.

Szpyra-Kozłowska, J. (2015). Pronunciation in EFL Instruction: A Research-Based Approach. Bristol, Buffalo, Toronto: Multilingual Matters.

Święciński, R. (2004). Articulatory setting in Polish and its implications for teaching English pronunciation to Poles. Zeszyty Naukowe PWSZ w Koninie 1/2004(4), 141-150.

Wrembel, M. (2002). Miejsce fonetyki języka angielskiego w szkole - implikacje dla kształcenia nauczycieli. In W. Sobkowiak, E. Waniek-Klimczak (eds), Dydaktyka fonetyki języka obcego. Płock: Wydawnictwo PWSZ w Płocku, 29-40. 
Wrembel, M. (2005). Metacompetence-oriented model of phonological acquisition: Implications for the teaching and learning of second language pronunciation. Proceedings of Phonetics Teaching and Learning Conference. London 2005, 1-5.

Wrembel, M. (2010). Sound symbolism in foreign language phonological acquisition. Research in Language 8, 175-188.

Appendix 1. The diagnostic passage

Arthur, his brother and their father and mother, who were both advertising managers, moved to another town last year. His mother was an excellent organizer so they quickly sorted out and packed their stuff, loaded it into a van and sent it to their new place, which had already been prepared for them. Since then Arthur's life changed a lot, but he adjusted fast to the new situation. He found his new school challenging, but also a bit terrifying. His maths teacher Mr Jones was very strict. On the first day of school he said to his thirty three pupils: "You must stop being childish and should work hard. You can learn here many absolutely fascinating things: how to do addition, subtraction, multiplication and division. Your development and progress will be constantly watched and judged carefully. No laziness could be tolerated. You must accept the new rules. You should and you can."

Appendix 2. A list of items employed in the experiment:

1. The interdental fricatives: Arthur, brother, father, both, another, mother, maths, thirty, three, things

2. The palatoalveolars: managers, adjusted, situation, teacher, Jones, childish, addition, subtraction, multiplication, division

3. Inflected verbs: moved, sorted, packed, loaded, prepared, changed, adjusted, watched, judged, tolerated

4. Strong and weak forms: you must stop, you should work hard, you can learn here, could be tolerated, must accept, you should, you can

5. Word stress: advertising, managers, organizer, challenging, fascinating, terrifying, absolutely, development, constantly, tolerated 